\title{
Autophagy and cell death in model organisms
}

\author{
N Kourtis ${ }^{1}$ and N Tavernarakis ${ }^{* 1}$
}

\begin{abstract}
Autophagy evolved in unicellular eukaryotes as a means for surviving nutrient stress. During the course of evolution, as multicellular organisms developed specialized cell types and complex intracellular signalling networks, autophagy has been summoned to serve additional cellular functions. Numerous recent studies indicate that apart from its pro-survival role under nutrient limitation, autophagy also participates in cell death. However, the precise role of this catabolic process in dying cells is not fully understood. Although in certain situations autophagy has a protective function, in other types of cell death it actually contributes to cellular destruction. Simple model organisms ranging from the unicellular Saccharomyces cerevisiae to the soil amoeba Dictyostelium discoideum and the metazoans Caenorhabditis elegans and Drosophila melanogaster provide clearly defined cell death paradigms that can be used to dissect the involvement of autophagy in cell death, at the molecular level. In this review, we survey current research in simple organisms, linking autophagy to cell death and discuss the complex interplay between autophagy, cell survival and cell death.
\end{abstract}

Cell Death and Differentiation (2009) 16, 21-30; doi:10.1038/cdd.2008.120; published online 22 August 2008

Autophagy is a self-degradation process that is essential for survival, differentiation, development, and homeostasis. There are at least three forms of autophagy - chaperonemediated autophagy, microautophagy, and macroautophagy - that differ with respect to their mechanisms, physiological functions and cargo specificity. In the best-studied form of autophagy, macroautophagy (herein referred to as autophagy), parts of the cytoplasm, long-lived proteins and intracellular organelles are sequestered within cytoplasmic double-membrane vesicles called autophagosomes or autophagic vacuoles. These characteristic vacuoles are finally delivered to lysosomes for bulk degradation (Figure 1).

Autophagy was discovered in mammalian cells and has been extensively investigated in yeast. ${ }^{1}$ These studies have identified many genes encoding proteins involved in autophagy (ATG proteins). ${ }^{2}$ ATG proteins participate in the induction of autophagy, the formation, expansion and maturation of autophagosomes, and in the retrieval of autophagic proteins from mature autophagosomes. ${ }^{3}$ Fusion processes occur through the t- and v-SNARE complexes, and other molecules, such as the Rab GTPases and components of the vacuolar protein-sorting (VPS) complex. Several protein kinases regulate autophagy, the best characterized being the mammalian target of rapamycin (mTOR), which negatively regulates the pathway. ${ }^{4}$ Downstream of TOR kinase, numerous proteins encoded by ATG genes (more than 20 genes in yeast) are essential for the execution of autophagy. ${ }^{5}$ The autophagic process is evolutionarily conserved and most yeast ATG genes have homologues in higher organisms (Table 1).

Autophagy has also been linked to cell death pathways. Indeed, excess cytoplasmic vacuolation is the main feature of type II programmed cell death or autophagic cell death. Both protective and destructive contributions of autophagy during cell death have been reported. ${ }^{6-8}$ In the following sections we consider the involvement of autophagic mechanisms in cell death pathways, in simple model organisms.

\section{Autophagy in Cell Survival}

Autophagy probably evolved as a cellular mechanism for surviving nutrient shortage in the extracellular environment. Autophagy transpires at low basal levels in all cells to serve homeostatic functions such as cytoplasmic, protein and organelle turnover. Autophagy is rapidly upregulated when cellular energy demands are increased and cannot be met by the nutrient supply, for example during starvation. In addition, autophagy acts as a pro-survival process in response to different forms of stress, including growth factor depletion, hypoxia, endoplasmic reticulum (ER) stress, microbial

\footnotetext{
${ }^{1}$ Institute of Molecular Biology and Biotechnology, Foundation for Research and Technology-Hellas, Heraklion 71110, Crete, Greece

*Corresponding author: N Tavernarakis, Institute of Molecular Biology and Biotechnology, Foundation for Research and Technology-Hellas, N Plastira 100, Vassilika Vouton, PO Box 1385, Heraklion 71110, Crete, Greece. Tel: + 30281039 1066; Fax: + 30281039 1067; E-mail: tavernarakis@imbb.forth.gr

Keywords: apoptosis; autophagy; Caenorhabditis elegans; excitotoxicity; necrosis; neurodegeneration

Abbreviations: APAF, apoptotic protease activating factor; ATG, autophagy-related genes; Bak, Bcl-2 homologous antagonist/killer; Bax, Bcl-2-associated X protein; $\mathrm{BCl}-\mathrm{X}_{\mathrm{L}}$, Basal cell lymphoma-extra large; BEC, beclin; BH3, Bcl-2 homology region 3; CED, cell death abnormality; DEG, degenerin ion channel family; DIF, differentiation-inducing factor; EGL, egg laying defective; ER, endoplasmic reticulum; IP3R, 1,4,5-triphosphate receptor; JNK, Jun N-terminal kinase; LGG, LC3/ GABARAP/GATE-16 family; MEC, mechanosensory abnormality; MEFs, mouse embryonic fibroblasts; polyQ, polyglutamine; Rab, ras in the brain; RIP, receptorinteracting protein; siRNA, small interfering RNA; SNARE, SNAP receptors; TOR, target of rapamycin; UNC, uncoordinated; UPS, ubiquitin-proteasome system; Uth1, youth 1; VPS, vacuolar protein-sorting; zDEVD-fmk, benzyloxycarbonyl-Asp-Glu-Val-Asp-fluoromethylketone

Received 03.6.08; revised 04.7.08; accepted 10.7.08; Edited by G Kroemer; published online 22.8.08
} 


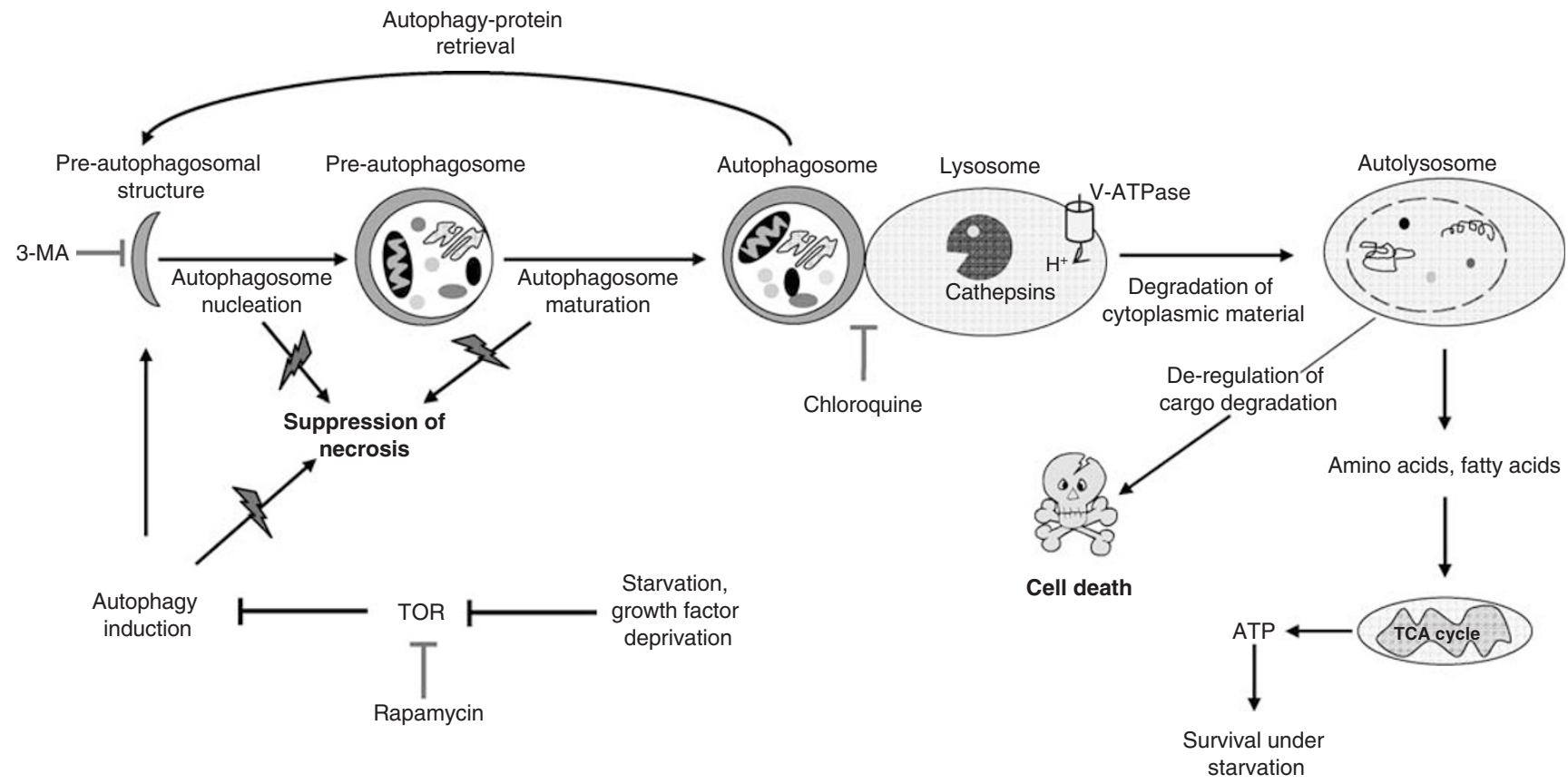

Figure 1 Interfacing the core autophagic pathway with cell death mechanisms. Starvation or growth factor deprivation triggers autophagy by modifying TOR signaling Autophagy involves the sequestration of portions of the cytoplasm within a double-membrane autophagic vacuole, called autophagosome. The autophagosome undergoes fusion with a lysosome, to form an autolysosome, in which hydrolases degrade the cytoplasmic material. Free fatty acids and amino acids generated in the process can be reutilized by the cell to maintain ATP levels and protein synthesis, promoting cell survival. Certain autophagy proteins are retrieved from autophagosomes and reused. The mechanism of autophagy protein retrieval is not well understood. Mutations that perturb various steps of the autophagy pathway result in suppression of necrotic cell death triggered by diverse stimuli. Pharmacological inhibitors are capable of inhibiting distinct steps of the autophagic pathway (red blocking arrows). TCA: tricarboxylic acid

infection and diseases characterized by the accumulation of protein aggregates. $^{9-12}$ This bulk form of macromolecule and organelle catabolism generates free amino and fatty acids, which are necessary metabolic substrates for adaptation to stress.

The role of autophagy in maintaining macromolecular synthesis and ATP production is likely a critical mechanism underlying its evolutionary conserved function. In single-cell organisms such as yeast, the response to starvation is one of the primary functions of autophagy. Genetic screens for mutants defective in survival on nitrogen-poor media, led to the identification of several autophagy genes. ${ }^{13-15}$ Many of these genes are conserved and function in the autophagic catabolic process in diverse phyla such as plants, worms, flies and mammals. ${ }^{5}$ In nitrogen-starved yeast, loss-of-autophagy results in death, defective sporulation (a process induced by nutrient starvation) and differentiation. ${ }^{15}$

Autophagy is also important for the response of Dictyostelium discoideum, a soil amoeba that feeds on bacteria, to starvation. Under nutrient limitation, Dictyostelium completes a complex developmental cycle to produce a multicellular organism, a process that requires autophagy. Mutations in the Dictyostelium autophagy gene orthologues ATG5, ATG6, ATG7 and ATG8 have subtle effects on growth in the presence of nutrients, but survival during nitrogen starvation is severely reduced. ${ }^{16,17}$

Loss-of-function mutations in ATG genes in plants reduce tolerance to nitrogen or carbon depletion, resulting in enhanced chlorosis, reduced seed set, accelerated leaf senescence and limited lateral root elongation. ${ }^{18-20}$ Autophagy is rapidly induced during exposure of Arabidopsis seedlings to oxidative stress. Transgenic plants defective in autophagosome formation are hypersensitive to oxidative stress and accumulate a higher level of oxidized proteins because of a lower degradation rate. These findings suggest that autophagy plays a role in eliminating damaged proteins during oxidative stress. ${ }^{21}$

Physiological levels of autophagy promote optimal survival of $C$. elegans during starvation, whereas insufficient or excessive levels of autophagy render animals hypersensitive to starvation. ${ }^{22}$ Autophagy is also upregulated during developmental transitions. In $C$. elegans the dauer larval stage is a quiescent, long-term survival diapause phase induced by nutrient deprivation, increased temperature and low insulin signalling. Inactivation of $C$. elegans ATG genes does not affect the initiation of dauer formation, but blocks dauer morphogenesis, inhibits autophagy in the seam cells (a cell type responsible for the formation of the specialized dauer cuticle) and prevents dauer survival. ${ }^{23}$

In mice, there is a massive increase in autophagy immediately after birth in various tissues. Neonates depend upon amino acids produced by autophagic degradation for the maintenance of energy homeostasis during neonatal starvation. ${ }^{24}$ The role of autophagy in development is not restricted to developmental changes that occur in the presence of stress conditions. Impairment of autophagy gene function results in lethality during early development even in the presence of normal growth conditions. In Drosophila, RNAi against the 
Table 1 Autophagy-related genes in higher eukaryotes

\begin{tabular}{|c|c|c|c|c|c|c|}
\hline \multicolumn{6}{|c|}{ Organism } & \multirow[t]{2}{*}{ Protein function } \\
\hline $\begin{array}{l}\text { Saccharomyces } \\
\text { cerevisiae }\end{array}$ & $\begin{array}{l}\text { Arabidopsis } \\
\text { thaliana }\end{array}$ & $\begin{array}{l}\text { Dictyostelium } \\
\text { discoideum }\end{array}$ & $\begin{array}{l}\text { Caenorhabditis } \\
\text { elegans }\end{array}$ & $\begin{array}{l}\text { Drosophila } \\
\text { melanogaster }\end{array}$ & $\begin{array}{l}\text { Mus } \\
\text { musculus }\end{array}$ & \\
\hline \multicolumn{7}{|c|}{ Regulation of autophagy induction } \\
\hline TOR & AtTOR & DdTOR & let-363 & DrTOR & mTOR & $\begin{array}{l}\text { Protein kinase; negative } \\
\text { regulator of autophagy }\end{array}$ \\
\hline ATG1 & $\begin{array}{l}\text { AtATG } \\
\text { (multiple isoforms) }\end{array}$ & DdATG1 & unc-51 & DrATG1 & munc51.2 & Ser/Thr protein kinase \\
\hline ATG11 & AtATG11 & - & - & - & - & $\begin{array}{l}\text { Peripheral membrane protein; } \\
\text { interacts with ATG1; required } \\
\text { for Cvt pathway }\end{array}$ \\
\hline ATG19 & - & - & - & - & - & $\begin{array}{l}\text { Cargo receptor; required for } \\
\text { Cvt pathway }\end{array}$ \\
\hline \multicolumn{7}{|c|}{ Autophagosome nucleation } \\
\hline ATG6 & $\begin{array}{l}\text { AtATG6 } \\
\text { (two predicted splice } \\
\text { variants) }\end{array}$ & DdATG6 & bec-1 & DrATG6 & beclin-1 & $\begin{array}{l}\text { Component of class III } \\
\text { PI3-kinase complex }\end{array}$ \\
\hline VPS34 & AtVPS34 & - & vps-34 & - & - & Class III PIE-kinase \\
\hline ATG14 & - & - & - & - & - & $\begin{array}{l}\text { Subunit of the PI-3-K catalytic } \\
\text { subunit }\end{array}$ \\
\hline \multicolumn{7}{|c|}{ Autophagosome expansion and completion } \\
\hline ATG3 & AtATG3 & DdATG3 & Y55F3AM.4 & DrAUT1 & mAPG3 & $\begin{array}{l}\text { E2 like enzyme; conjugates } \\
\text { ATG8 to PE }\end{array}$ \\
\hline ATG4 & $\begin{array}{l}\text { AtATG4 } \\
\text { (multiple isoforms) }\end{array}$ & DdATG4 & Y87G2A.3 & APG4/AUT2 & mAPG4 & $\begin{array}{l}\text { Cys protease; cleaves at } \\
\text { C terminus of ATG8 }\end{array}$ \\
\hline ATG5 & AtATG5 & DdATG5 & atgr -5 & DrATG5 & mAPG5 & $\begin{array}{l}\text { Conjugated to ATG12 through } \\
\text { internal lysine }\end{array}$ \\
\hline ATG7 & AtATG7 & DdATG7 & atgr-7 & DrATG7 & $m A P G 7$ & $\begin{array}{l}\text { E1-like enzyme; activates ATG8 } \\
\text { and ATG12 }\end{array}$ \\
\hline ATG8 & $\begin{array}{l}\text { AtATG8 } \\
\text { (multiple isoforms) }\end{array}$ & DdATG8 & $\operatorname{lgg}-1$ & DrATG8 & $m A P G 8$ & $\begin{array}{l}\text { Ubiquitin-like protein conjugated } \\
\text { to } \mathrm{PE}\end{array}$ \\
\hline ATG10 & $\begin{array}{l}\text { AtATG10 } \\
\text { (two predicted splice } \\
\text { variants) }\end{array}$ & - & D2085.2 & DrATG10 & mAPG10 & $\begin{array}{l}\text { E2-like enzyme; conjugates } \\
\text { ATG12 to ATG5 }\end{array}$ \\
\hline ATG12 & $\begin{array}{l}\text { AtATG12 } \\
\text { (multiple isoforms) }\end{array}$ & DdATG12 & $\operatorname{lgg}-3$ & DrATG12 & $m A P G 12$ & $\begin{array}{l}\text { Ubiquitin-like protein conjugated } \\
\text { to ATG5 }\end{array}$ \\
\hline ATG13 & $\begin{array}{l}\text { Two potential genes } \\
\text { with restricted } \\
\text { similarity }\end{array}$ & - & - & - & - & $\begin{array}{l}\text { Phosphoprotein; } \\
\text { dephosphorylated under } \\
\text { starvation conditions }\end{array}$ \\
\hline ATG16 & - & - & K06A1.5 & - & $m A P G 16$ & $\begin{array}{l}\text { Component of ATG12-ATG5 } \\
\text { complex }\end{array}$ \\
\hline ATG17 & - & - & - & & & Interacts with ATG1, \\
\hline \multicolumn{7}{|c|}{ Retrieval of autophagic proteins } \\
\hline $\begin{array}{l}\text { ATG2 } \\
\text { ATG9 }\end{array}$ & $\begin{array}{l}\text { AtATG2 } \\
\text { AtATG9 }\end{array}$ & $\begin{array}{l}\text { DdATG2 } \\
\text { DdATG9 }\end{array}$ & $\overline{\operatorname{atgr}-9}$ & $\begin{array}{l}\text { DrATG2 } \\
\text { DrATG9 }\end{array}$ & $\begin{array}{l}\text { mAPG2 } \\
\text { mAPG9 }\end{array}$ & $\begin{array}{l}\text { Interacts with ATG9 } \\
\text { Integral membrane protein; } \\
\text { interacts with ATG2 and ATG23 }\end{array}$ \\
\hline ATG18 & AtATG18 & - & atgr-18 & - & - & Required for ATG2 localization \\
\hline
\end{tabular}

Apart from the genes that have been directly implicated in autophagy, those identified through interactions with autophagy-related proteins or by sequence similarity searches are included.

homologue of the yeast Aut1 (ATG3) gene causes inability to induce autophagy in fat body cells before pupariation and animals die during metamorphosis. ${ }^{25}$ Thus, when the supply of environmental nutrients is limited, autophagy can generate a source of metabolic substrates to maintain cellular ATP production, protein, and fatty acid synthesis, to meet cellular and organism energy and metabolic demands.

Autophagy is also involved in the response to intracellular stress conditions (e.g., accumulation of abnormal protein aggregates, damaged or superfluous organelles and intracellular pathogens). In the absence of autophagy, the turnover of cytosolic proteins is impaired, increasing their propensity to become damaged, misfolded and subsequently ubiquitinated and aggregated. ${ }^{26,27}$ Basal levels of autophagy may be particularly essential for post-mitotic cells, which cannot redistribute and dilute damaged organelles, proteins and aggregates through cell division. In contrast to the ubiquitinproteasome system (the other major protein degradation system), autophagic breakdown of substrates is not limited by steric considerations and therefore it is uniquely capable of degrading whole organelles such as mitochondria (mitophagy), peroxisomes (pexophagy), and ER (reticulophagy). Thus, basal and induced autophagy are important for the physiological control of the number and quality of organelles in diverse phyla and function to eliminate superfluous, aged and damaged organelles and proteins. 


\section{Autophagy in Cell Death}

Although primarily a homeostatic response, autophagy has been adapted to serve additional cellular functions. The presence of autophagic structures in dying cells, in diverse organisms has implicated autophagy in the cell death process. Cell death is of paramount importance both for the development and also during the adult life of animals, by forming and deleting structures, controlling cell numbers, eliminating abnormal or damaged cells and contributing in many pathological situations. Three major types of cell death have been defined based on morphological criteria. ${ }^{28}$ Type 1 programmed cell death (or apoptosis) is characterized by dependence on caspases, chromatin condensation and fragmentation and overall cell shrinkage. Blebbing of the plasma membrane leads to the formation of apoptotic bodies, which are ingested by phagocytes. Type 2 (or autophagic cell death) is characterized by increased number of autophagosomes that are used for self-degradation. This process is independent of phagocytes. In type 3 (or necrotic cell death), several intracellular organelles dilate and the plasma membrane breaks down, causing spillage of cytoplasmic content and inflammation.

Based on morphologic criteria, it has been widely recognized that autophagic cell death occurs primarily during developmental periods that require massive cell elimination (e.g., insect metamorphosis). Both caspase activation and autophagic vacuole formation occur during autophagic cell death of Drosophila salivary glands and midguts. ${ }^{29-31}$ However, in certain cases, autophagy per se is neither sufficient nor required for cell death. In addition, during salivary gland regression in Drosophila, the caspase inhibitor p35 blocks metamorphic cell death, suggesting that this cell death programme is executed primarily by apoptosis, rather than autophagy. ${ }^{29}$ Furthermore, this process is associated with the transcriptional upregulation of pro-apoptotic molecules such as grim, reaper, hid the caspases dronc and $d c p-1$ and the ced-4/apaf-1 homologue dark/ark and the downregulation of an apoptosis inhibitor diap 2. ${ }^{29,32-34}$ Direct induction of autophagy by ATG1 overexpression in Drosophila, demonstrates that autophagy is sufficient to induce cell death. Importantly, the ensuing cell death is caspase-dependent and displays apoptotic features, supporting the concept that in animal cells autophagy can induce apoptosis, instead of being a distinct form of cell death. ${ }^{35}$ Whether in certain cases autophagy occurs in parallel to the apoptotic pathway, or autophagosome formation is a consequence of caspase activation, or autophagy triggers apoptosis, remains to be clarified.

Dictyostelium offers a particularly advantageous platform to isolate and dissect the mechanisms of autophagic cell death because the Dictyostelium genome does not encode components of the apoptotic pathway. In addition, caspase activity is not required for Dictyostelium cell death ${ }^{36}$ and the single Dictyostelium paracaspase gene that has been identified is not required, either for autophagic cell death or for necrotic cell death. ${ }^{37,38}$ Therefore, apoptosis does not interfere with autophagic cell death in this organism. Dictyostelium displays developmental cell death, ${ }^{39}$ which can be mimicked under in vitro monolayer conditions, where Dictyostelium cells are subjected to starvation and the differentiation-inducing factor (DIF-1). ${ }^{40}$ This type of cell death is autophagic, characterized by vacuolation ${ }^{41}$ and requires an inositol 1,4,5-triphosphate receptor (IP3R), which governs $\mathrm{Ca}^{2+}$ fluxes from the endoplasmic reticulum (ER) stores into the cytosol. ${ }^{42}$ Random mutagenesis provides a very powerful tool for the dissection of cell death in Dictyostelium. ${ }^{43} \mathrm{~A}$ null mutation in the autophagy gene ATG1 blocks autophagy and vacuolization, in the above model, but not cell death. ${ }^{44}$ This non-vacuolar cell death demonstrates classical characteristics of necrotic cell death such as rapid generation of reactive oxygen species, ATP depletion, perinuclear clustering of mitochondria, and plasma membrane rupture. ${ }^{45}$

The intrinsic pathway that leads to caspase-dependent apoptosis is characterized by mitochondrial outer membrane permeabilization and the release of mitochondrial cytochrome $c$, which results in the formation of a caspase-activating complex encompassing caspase-9 and APAF-1. Expression of the human pro-apoptotic Bax protein in yeast induces growth arrest and loss of yeast cell plating efficiency. In yeast, Bax can be translocated to the outer mitochondrial membrane to form a high conductance channel and to facilitate cytochrome $c$ release. This observation indicates that a primitive form of apoptosis exists in yeast. As mitochondrial damage is a critical, life-threatening condition for the cell, the autophagic process may play an important role in assisting cells to remove injured mitochondria and to regulate their turnover. The yeast gene Uth1 encodes an outer mitochondrial membrane protein involved in mitochondrial biogenesis and stress responses. In the absence of Uth1p, mutants exhibit resistance to autophagy induced by rapamycin. ${ }^{46}$ Uth $1 p$ is therefore the first mitochondrial protein shown to be required for the autophagic degradation of mitochondria. In addition, Uth1 mutants survive and proliferate when expressing the human proapoptotic cell death gene bax. $^{47}$ The totality of these findings suggests that Uth $1 \mathrm{p}$ may provide a direct association between mitophagy and cell death.

Beclin-1 is essential for the initiation of autophagy, perhaps through its interaction with the class III phosphatidylinositol-3kinase Vps34. ${ }^{48}$ The antiapoptotic proteins $\mathrm{Bcl}-2$ and $\mathrm{Bcl}-\mathrm{X}_{\mathrm{L}}$ bind Beclin-1 and inhibit its autophagic activity. This interaction involves a $\mathrm{BH} 3$ domain within Beclin-1 and a $\mathrm{BH} 3$ receptor domain within $\mathrm{Bcl}-\mathrm{X}_{\mathrm{L}}$. Disruption of this interaction by $\mathrm{BH} 3-$ only proteins or $\mathrm{BH} 3$ mimetics induces autophagy. ${ }^{49}$ Interestingly, the beclin-1-BCL-2/BCL- $X_{L}$ complexes that normally inhibit autophagy are specifically located in the ER and not in the mitochondria. These findings suggest that $\mathrm{BH} 3-$ only proteins represent a link between self-killing and selfeating. Beclin-1 was also found to interact with $\mathrm{Bcl}-2$ and to protect neuronal cells against virus-induced apoptotic cell death. ${ }^{50}$ This interaction is also conserved in C. elegans where BEC-1 (the nematode orthologue of Beclin-1) interacts with CED-9, (the C. elegans orthologue of Bcl-2)..$^{51} \mathrm{Nema-}$ todes lacking bec-1, display increased caspase-dependent apoptosis and an elevated number of apoptotic cell corpses in embryonic tissues, revealing a role for BEC-1 in apoptosis. Taken together, these observations indicate that Beclin is a central node coordinating the involvement of autophagy in cell death (Figure 2). 


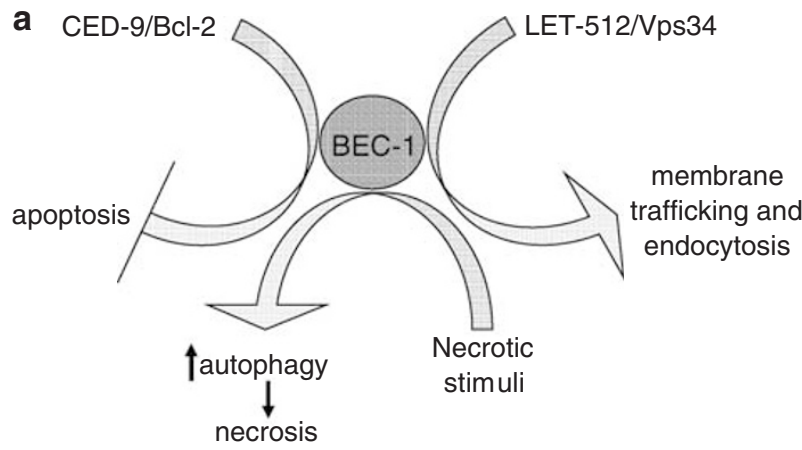

b

$$
\text { Starvation } \stackrel{E G L-1}{\longrightarrow} \longrightarrow \text { autophagy }
$$

Figure 2 Distinct intracellular cell death pathways and autophagy share common proteins. (a) The autophagy protein BEC-1 participates, through different complexes, in the regulation of apoptosis, the induction of autophagy after necrotic insults, and in physiological autophagy functions. BEC-1 regulates apoptosis through complex formation with the antiapoptotic CED-9, providing a direct link between autophagy and apoptosis. Disruption of bec-1 triggers apoptosis in C. elegans. BEC-1 is also required for autophagy induction in response to diverse necrotic stimuli. Inactivation of bec-1 suppresses necrosis. ${ }^{52,53}$ In addition, BEC-1 interacts with LET-512, the $C$. elegans ortholog of the yeast phosphatidylinositol (Ptdlns) 3-kinase Vps34, and this interaction is necessary for membrane-trafficking and endocytosis. (b) The EGL-1 protein, an activator of programmed cell death, modulates starvation-induced autophagy in $C$. elegans. Depletion of EGL-1 results in limited induction of autophagy after starvation

Many paradigms of programmed cell death in plants display typical morphological features of autophagic cell death. ${ }^{54}$ Upon infection by the tobacco mosaic virus, cells elicit the hypersensitive response, a form of programmed cell death, as a means of limiting pathogen spread. A high-throughput virus-induced gene silencing screen to identify genes involved in programmed cell death during the hypersensitive response to pathogen infection led to the isolation of an ATG6/Beclin-1 homologue. Silencing of this gene does not affect the death of infected cells or pathogen spread but causes cell death lesions to spread beyond the infection site, and even to uninfected leaves. These results suggest that Beclin-1 is required for restriction of cell death to the site of infection. ${ }^{55}$ The mechanism by which autophagy prevents the spread of cell death is not clear. One possibility is that autophagy contributes to the degradation and removal of death-promoting signals, preventing their dispersal to uninfected cells. Alternatively, autophagy may protect healthy cells from damage caused by reactive oxygen intermediates produced during the defence response.

\section{Autophagy-Apoptosis Interplay}

The interplay between autophagy and apoptosis is complex and not fully understood. The two processes are regulated by common factors and share common components, whereas the activity of one can regulate the activity of the other. Several pro-apoptotic signals (e.g., those transduced by BH3only proteins) induce autophagy, whereas signals that inhibit apoptosis (e.g., through Bcl-2 family members) also inhibit autophagy. An additional finding supporting a direct molecular link between autophagy and apoptosis is the observation that ATG5 can undergo calpain-mediated cleavage to generate a pro-apoptotic fragment that functions in the intrinsic mitochondrial death pathway. ${ }^{56}$ The overlap between the molecular mechanisms mediating autophagic cell death and apoptosis is also reflected in the results of microarray studies and serial analysis of gene expression during developmental programmed cell death of the Drosophila salivary glands, where genes involved in both apoptosis and autophagy share similar expression profiles. ${ }^{32,34}$

Several apoptotic stimuli can promote compensatory autophagic cell death, in particular when the apoptotic pathway is impaired. Suppression of caspase-8 activity induces non-apoptotic cell death in mouse $L 929$ cells. ${ }^{57}$ These cells display loss of membrane integrity and accumulation of autophagosome-like vesicles in the cytoplasm. Execution of cell death requires activation of a pathway involving RIP and components of the Jun $\mathrm{N}$-terminal kinase pathway, and is reduced by downregulation of the autophagy genes ATG7 and beclin-1. Moreover, elimination of the pro-apoptotic proteins Bax and Bak sensitizes specific cell types to autophagic demolition. Bax- and Bak-deprived mouse embryonic fibroblasts (MEFs) treated with apoptotic stimuli (etoposide or staurosporine), or exposed to radiation, fail to undergo apoptosis and instead manifest increased autophagy accompanied by delayed cell death ${ }^{58,59}$ Knockdown of key genes in the autophagic pathway attenuated etoposide-induced cell death of $\mathrm{Bax}^{-I} \mathrm{Bak}^{-1}$ MEFs. These findings indicate that autophagy acts as a 'fail-safe' mechanism to ensure the demolition of the cells destined to die. Surprisingly, treatment with siRNA against $\mathrm{Bcl}-\mathrm{X}_{\mathrm{L}}$ protects these cells against nonapoptotic death, whereas overexpression of $\mathrm{Bcl}-2$ or $\mathrm{Bcl}-\mathrm{X}_{\mathrm{L}}$ sensitizes wild type MEFs to autophagy. ${ }^{59}$ Together, these data raise the possibility that the mode of programmed cell death is determined in part by the levels of pro- and antiapoptotic signals.

Autophagic death is also inflicted by exposure of apoptosisdefective mammalian cells to histone deacetylase inhibitors. ${ }^{60}$ Furthermore, in murine leukaemia cells, treatment with Bcl-2, $\mathrm{Bcl}-\mathrm{X}_{\mathrm{L}}$ antagonists causes a rapid increase in autophagosome formation and apoptosis. ${ }^{61}$ In addition, administration of the autophagy inhibitor wortmanin promotes apoptosis, whereas treatment with the caspase-3/7 suppressor ZDEVDfmk promotes autophagy. Thus, cells can compensate for potential deficiencies in programmed apoptotic death mechanisms by activating alternative autophagic death pathways. What are the mechanisms through which the inhibition of autophagy may favour cell death? One possibility is that inhibition of autophagy perturbs energetic homeostasis and triggers apoptosis. Moreover, inhibition of autophagy may impair the capacity of cells to remove damaged organelles and misfolded proteins, which in turn disrupts homeostasis and elicits apoptosis.

\section{Autophagy-Necrosis Interplay}

Several studies have revealed that autophagy is upregulated by necrosis-inducing stimuli. Traumatic brain injury in mice leads to elevation of Beclin-1 levels in neurons and in astrocytes. ${ }^{62,63}$ Dying brain cells of adult mice subjected to 
unilateral common carotid artery occlusion display cytoplasmic vacuolization, lysis of intracellular organelles and activated autophagy. ${ }^{64}$ In addition, autophagy upregulation occurs in murine and chicken models of excitotoxicity. ${ }^{65-67}$ Although in some cases autophagosomes accumulate mostly in neuronal axons, in others they gather in the perinuclear region. ${ }^{66,67}$ Activation of $\mathrm{RIP}$, a component of the Jun $\mathrm{N}$-terminal kinase (JNK) pathway, in mammalian cells treated with caspase inhibitors also causes toxicity characterized by excess autophagosome formation. ${ }^{57}$ The JNK pathway has been associated with caspase-independent necrotic-like damage. ${ }^{68-70}$

Although autophagy is upregulated in the above cases, it was not clear whether it protects cells or contributes to their destruction. Recent studies in $C$. elegans indicate a causative role of autophagy in necrotic cell death. ${ }^{71,52}$ Impairment of autophagy by downregulation of the autophagy genes bec-1, unc-51 and lgg-1 or pharmacological treatment interfering with autophagy partially suppresses necrotic neuronal death induced by hyperactive MEC-4, DEG-1 and DEG-3 ion channels. In contrast, autophagy upregulation by knockdown of the negative autophagy regulator CeTOR or under nutrient deprivation promotes neuron necrosis. Autophagy synergizes with Iysosomal proteolytic pathways to facilitate necrotic cell death (Figure 3). ${ }^{71}$

\section{Autophagy and Neurodegenerative Conditions}

Several progressive neurodegenerative disorders are associated with accumulation of expanded polyglutamine repeat (polyQ) proteins. ${ }^{72}$ Disease severity is correlated with the extent of polyQ expansion; longer polyQ stretches result in earlier onset and more severe symptoms. The mechanisms of pathogenesis underlying both polyQ expansion and toxicity are subject to intense study and several animal models have been developed and brought to bear on this question. ${ }^{73}$ The prominent autophagosome accumulation both in experimental models and in human brain autopsies has led to the concept that autophagy constitutes a form of nonprogrammed cell death that contributes to neurodegeneration. However, recent experimental evidence indicates that autophagy has a neuroprotective role by facilitating clearance of misfolded proteins and aggregates, a hallmark of many neurodegenerative diseases. These two roles of autophagy are not mutually exclusive, and it is possible that the autophagic response is initially activated as a housekeeping mechanism but may eventually contribute to neuropathology.

Misfolded proteins are targeted for degradation either through the ubiquitin-proteasome system (UPS) or the autophagic pathway. New findings now suggest that that these two pathways interact. Autophagy acts as a compensatory degradation system when the UPS is impaired in Drosophila. Histone deacetylase 6, a microtubule-associated deacetylase, provides an essential link between autophagy and the UPS in this system. ${ }^{74}$ In $C$. elegans, expression of proteins with expanded polyQ in the nervous system results in neuronal dysfunction and degeneration. Amino-terminal huntingtin fragments with varying polyglutamine repeat lengths have been expressed in nematode sensory neurons.
Fragments carrying the longest polyglutamine stretch (150 glutamine residues) inhibit neuronal function in an agedependent fashion. Toxicity is characterized by the formation of protein aggregates and loss of neuronal function, which precedes physical neuron degeneration. Direct evidence that autophagy plays a role in vivo in preventing the accumulation of polyQ protein aggregates and protecting against polyQ aggregate-induced disease, is provided from analysis of C. elegans polyQ expansion disease models. ${ }^{75}$ RNAi knockdown of different autophagy genes that act in distinct steps of the autophagy pathway increases the accumulation of protein aggregates in $C$. elegans muscle cells and sensory neurons and enhances their toxicity.

The abnormal accumulation of intracellular aggregates is a hallmark of disorders associated with expanded polyglutamine proteins. Whether the formation of these aggregates is protective or deleterious is not yet clear. mTOR is sequestered into polyglutamine aggregates in cell models, transgenic mice and human brains, leading to decreased mTOR activity. ${ }^{76}$ Impaired mTOR signalling induces autophagy and provides a molecular basis supporting a protective role of aggregate formation, through the indirect stimulation of autophagic clearance of mutant huntingtin fragments. The therapeutic potential of rapamycin a specific inhibitor of $\mathrm{mTOR}^{77}$ was tested in a fly model of Huntington's disease. Flies expressing mutant huntingtin exhibited markedly slower neurodegeneration, when treated with rapamycin. ${ }^{76}$ Subsequent studies in cell cultures and Drosophila have shown that rapamycin also protects against a range of pro-apoptotic insults and reduces paraquat toxicity. ${ }^{78} \mathrm{~A}$ loss-of-function mutation of ATG1 abolished the beneficial effect of rapamycin. The proposed mechanism is based on a reduction of mitochondrial load and consequently of cytochrome $c$ release. However, clearance of other non-mitochondrial pro-apoptotic proteins cannot be excluded. TOR, controls many cellular functions in addition to autophagy, including cell growth, protein translation, metabolism and cell death. Therefore, attempts to control autophagy through the manipulation of TOR activity need to take into consideration potential unpredictable and adverse effects.

A screen for autophagy enhancers using a library of FDAapproved drugs has identified the drugs minoxidil (an ATPsensitive $\mathrm{K}^{+}$channel agonist); clonidine (an $\alpha_{2}$-adrenergic and type I imidazoline receptor agonist); and verapamil (an L-type $\mathrm{Ca}^{2+}$ channel antagonist) as inducers of autophagy. This study reveals a new mTOR-independent pathway regulating autophagy, in which cAMP regulates $\mathrm{IP}_{3}$ levels and influences calpain activity, which in turn cleaves and activates $\mathrm{G}_{\mathrm{s} \alpha}$. The therapeutic relevance of the two identified compounds that induce autophagy has been verified using cell, fly and zebrafish models of Huntington's disease. ${ }^{79}$ Lithium also stimulates a novel mTOR-independent pathway that regulates autophagy and promotes aggregate clearance in cells and in Drosophila models of Huntington's disease. ${ }^{80}$ Finally, mutations that affect the dynein machinery impair autophagosome-lysosome fusion, leading to decreased autophagic clearance of aggregate-prone proteins and enhanced toxicity of the mutation that causes Huntington's disease in fly and mouse models. ${ }^{81}$ 


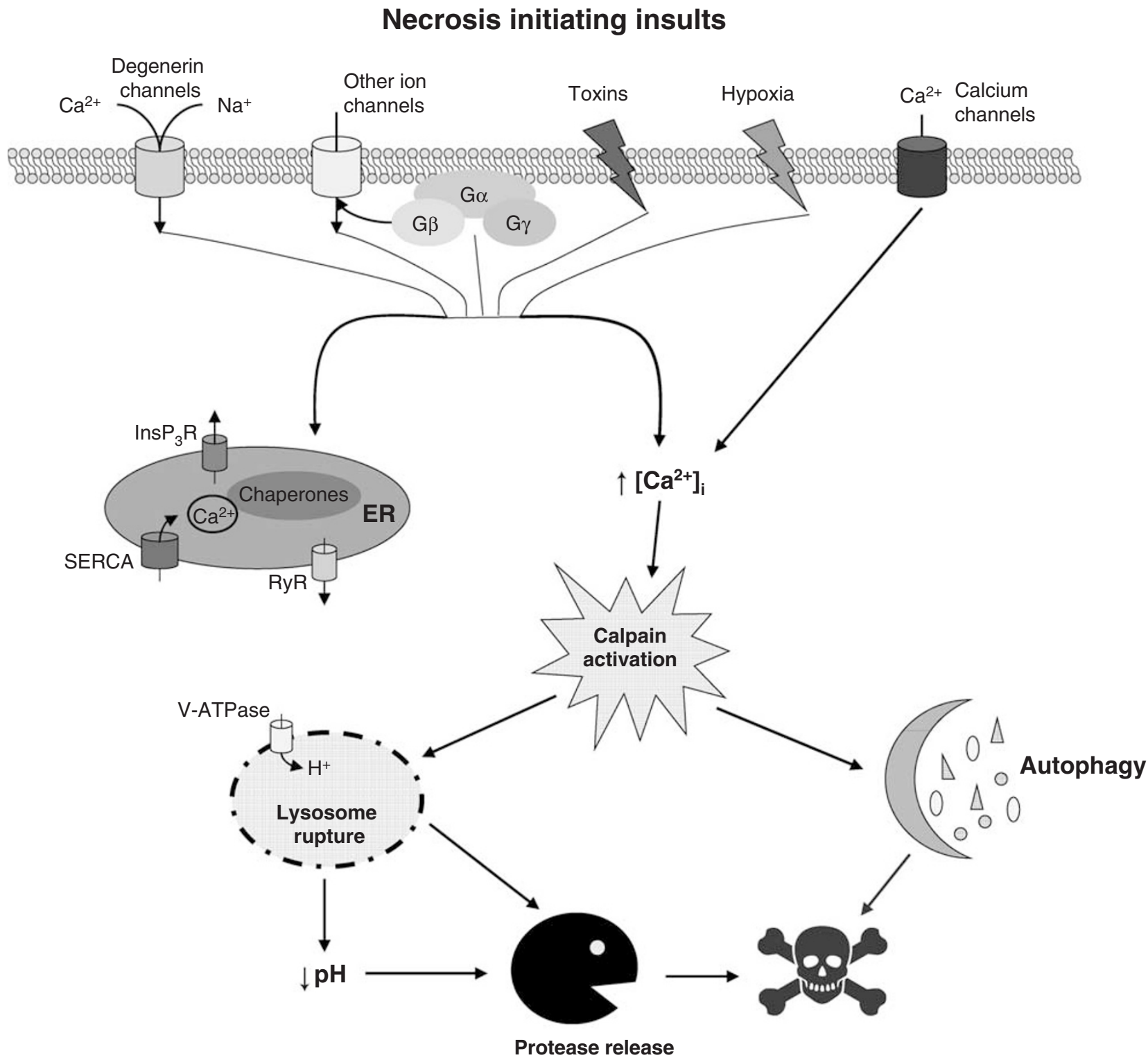

Figure 3 Autophagy is required for and is induced during neurodegeneration in C. elegans. Diverse genetic and environmental insults lead to increase of cytoplasmic calcium concentration. Intracellular calcium stores also contribute to the elevation of calcium concentration beyond tolerable levels. The channels and molecules known to be involved in calcium homeostasis are shown. Increased calcium concentration activates cytoplasmic calpain proteases, which facilitate lysosomal rupture and release of acidic lysosomal contents into the cytoplasm, which consequently becomes acidified. The valuolar $\mathrm{H}^{+}$ATPase (V-ATPase) pump is responsible for lysosomal and subsequent cytoplasmic acidification. Low pH conditions favour activation of cathepsin proteases and contribute to cellular destruction. Autophagy is upregulated upon induction of necrosis directly and/or through calpain activation and synergizes with lysosomal cathepsin proteases to mediate cell death. $\left[\mathrm{Ca}^{2+}\right]$ : cytoplasmic calcium concentration; ER: endoplasmic reticulum; InsP3R: inositol triposphate receptor; RyR: ryanodine receptor; SERCA: sarco-endoplasmic reticulum $\mathrm{Ca}^{2+}{ }_{\text {-ATPase; V-ATPase: vacuolar }}$ $\mathrm{H}^{+}$-ATPase

\section{Single Proteins: Multiple Roles}

In addition to the direct involvement of autophagy in cell death pathways, accumulating evidence suggests that components of the autophagic machinery may participate in cellular processes other than autophagy. Likewise, recent studies have shown that caspases, apart from their well known role in cell death execution, also regulate differentiation processes in Drosophila and participate in $\mathrm{T}$ and $\mathrm{B}$ lymphocyte activation and proliferation in humans. ${ }^{82,83}$ Moreover, EGL-1, the sole pro-apoptotic BH3-only protein in C. elegans which is required for developmental cell death in the nematode is also a mediator of starvation-induced autophagy. ${ }^{49}$ In addition, APAF-1, an essential factor for cytochrome $c$-driven caspase activation during mitochondrial apoptosis is also implicated in DNA damage-induced cell-cycle arrest. ${ }^{84}$ Likewise, ATG5, a gene product required for the formation of autophagosomes, is proteolytically activated to become a pro-apoptotic molecule that translocates from the cytocol to mitochondria and triggers cytochrome $c$ release and caspase activation. ${ }^{56}$ 
Mutations in the unc-51 gene, the $C$. elegans orthologue of yeast ATG1 result in various abnormalities in axonal elongation and axonal structures. This finding suggests a distinct additional role for unc-51 in axonal elongation. ${ }^{85}$ In addition, the identification of Drosophila ATG4 gene in a genetic screen for modifiers of developmental phenotypes of Notch-signalling mutants revealed an unexpected link between autophagy and the Notch-signalling pathway. ${ }^{86}$ Thus, a general caveat associated with overexpression or knockout of single ATG genes is that such interventions could have unpredictable indirect effects beyond those related with autophagy.

\section{Concluding Remarks and Outlook}

Despite the considerable recent advances, our understanding of the dual role of autophagy in cell survival and cell death remains incomplete. It is still not fully understood what factors determine whether autophagy is cytoprotective or cytotoxic and how autophagy contributes to death (Figure 4). In the absence of tight regulation, autophagy may exceed a crucial threshold, inadvertently causing the catabolism of cytoplasmic factors, regulatory molecules and organelles that are essential for survival. Moreover, autophagy may accelerate the apoptotic destruction of the cell by initiating the self-digestion of cells destined to die. Autophagy may also provide the cell with high ATP levels necessary for the energydependent apoptotic process. In several cases, morphologic features of both autophagic and apoptotic cell death, or autophagic and necrotic cell death are observed in the same cell.

Studies of autophagy in model organisms have revealed a great deal on the complex interplay between autophagy and cell death pathways. Autophagy has been shown to protect against cell demise in conditions of starvation, nutrient withdrawal, and neurodegeneration, ${ }^{26,27,87}$ but is also a critical contributing factor in certain types of cell death. ${ }^{57,59}$ It is likely that the dual role of autophagy in cell death is contextdependent. The presence of autophagic structures in dying cells is equally consistent with a causal, neutral, or inhibitory role of autophagy in cell death. The question of whether this is the result of increased autophagic activity or decreased autophagosome-lysosome fusion also needs to be taken into account. Thus to manipulate autophagy for therapeutic purposes, it is essential to consider both its cytoprotective

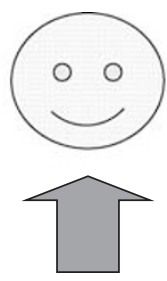

Protein and organelle turnover

Elimination of superfluous organelles

Elimination of aggregate-prone proteins

Generation of energy under nutrient limitation

Support of bioenergetic demands during developmental transitions

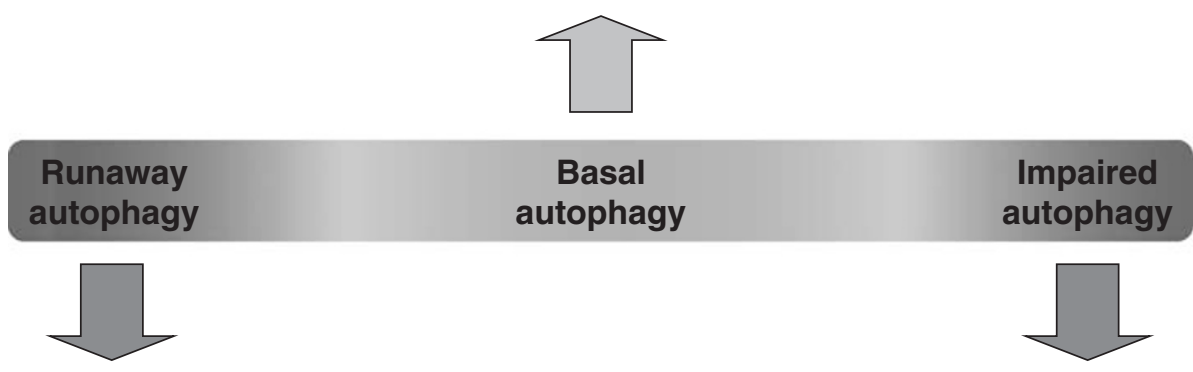

Catabolism of essential regulatory molecules and organelles Interference with pro-survival mechanisms

Digestion of anti-apoptotic molecules

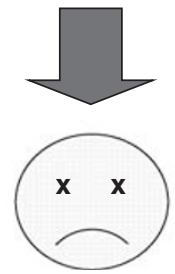

Accumulation of damaged intracellular components Aggregation of disease proteins Insufficient energy supplies

Figure 4 The role of autophagy in cell survival and death. Basal autophagy acts as a cytoprotective mechanism and serves homeostatic functions such as cytoplasmic, protein and organelle turnover. Moreover, autophagy provides metabolic substrates when cell energetic demands are increased, during developmental transitions or nutrient/ growth factor deprivation. Uncontrolled, 'runaway' autophagy can digest vital amounts of cell components and survival factors, thus leading to the demise of the cell. Similarly, impaired autophagy can be deleterious by allowing damaged proteins and organelles to accumulate and by failing to provide energy for essential cell functions 
and cytotoxic roles, and the additional caveat that blockage of one type of cell death may trigger compensatory celldestructive pathways. Simple model organisms, with their genetic malleability, provide ideal platforms for investigating these possibilities. Given the evolutionary conserved core autophagic and cell death mechanisms, this endeavour is likely to yield novel and valuable insights on role of autophagy in human disease.

Acknowledgements. This work in the authors' laboratory is supported by grants from EMBO, the Empeirikeion Foundation and the EU 6th Framework Programme. NK is a recipient of the Manasaki doctoral scholarship.

1. Huang WP, Klionsky DJ. Autophagy in yeast: a review of the molecular machinery. Cell Struct Funct 2002; 27: 409-420

2. Klionsky DJ, Cregg JM, Dunn Jr WA, Emr SD, Sakai Y, Sandoval IV et al. A unified nomenclature for yeast autophagy-related genes. Dev Cell 2003; 5: 539-545.

3. Klionsky DJ. The molecular machinery of autophagy: unanswered questions. J Cell Sci 2005; 118 (Part 1): 7-18.

4. Kamada Y, Funakoshi T, Shintani T, Nagano K, Ohsumi M, Ohsumi Y. Tor-mediated induction of autophagy via an Apg1 protein kinase complex. J Cell Biol 2000; 150 1507-1513.

5. Levine B, Klionsky DJ. Development by self-digestion: molecular mechanisms and biological functions of autophagy. Dev Cell 2004; 6: 463-477.

6. Baehrecke EH. Autophagy: dual roles in life and death? Nat Rev Mol Cell Biol 2005; 6 : 505-510.

7. Cuervo AM. Autophagy: many paths to the same end. Mol Cell Biochem 2004; 263: 55-72.

8. Shintani T, Klionsky DJ. Autophagy in health and disease: a double-edged sword. Science 2004; 306: 990-995.

9. Levine B, Yuan J. Autophagy in cell death: an innocent convict? J Clin Invest 2005; 115: 2679-2688.

10. Lum JJ, DeBerardinis RJ, Thompson CB. Autophagy in metazoans: cell survival in the land of plenty. Nat Rev Mol Cell Biol 2005; 6: 439-448.

11. Maiuri MC, Zalckvar E, Kimchi A, Kroemer G. Self-eating and self-killing: crosstalk between autophagy and apoptosis. Nat Rev Mol Cell Biol 2007; 8: 741-752.

12. Yorimitsu T, Nair U, Yang Z, Klionsky DJ. Endoplasmic reticulum stress triggers autophagy. J Biol Chem 2006; 281: 30299-30304.

13. Harding TM, Morano KA, Scott SV, Klionsky DJ. Isolation and characterization of yeast mutants in the cytoplasm to vacuole protein targeting pathway. J Cell Biol 1995; 131: 591-602.

14. Thumm M, Egner R, Koch B, Schlumpberger M, Straub M, Veenhuis $M$ et al. Isolation of autophagocytosis mutants of Saccharomyces cerevisiae. FEBS Lett 1994; 349: 275-280.

15. Tsukada M, Ohsumi Y. Isolation and characterization of autophagy-defective mutants of Saccharomyces cerevisiae. FEBS Lett 1993; 333: 169-174.

16. Otto GP, Wu MY, Kazgan N, Anderson OR, Kessin RH. Macroautophagy is required for multicellular development of the social amoeba Dictyostelium discoideum. J Biol Chem 2003; 278: 17636-17645.

17. Otto GP, Wu MY, Kazgan N, Anderson OR, Kessin RH. Dictyostelium macroautophagy mutants vary in the severity of their developmental defects. J Biol Chem 2004; 279: 15621-15629

18. Bassham DC. Plant autophagy - more than a starvation response. Curr Opin Plant Biol 2007; 10: 587-593.

19. Doelling JH, Walker JM, Friedman EM, Thompson AR, Vierstra RD. The APG8/12activating enzyme APG7 is required for proper nutrient recycling and senescence in Arabidopsis thaliana. J Biol Chem 2002; 277: 33105-33114.

20. Hanaoka H, Noda T, Shirano Y, Kato T, Hayashi H, Shibata D et al. Leaf senescence and starvation-induced chlorosis are accelerated by the disruption of an Arabidopsis autophagy gene. Plant Physiol 2002; 129: 1181-1193.

21. Xiong $Y$, Contento AL, Nguyen $P Q$, Bassham DC. Degradation of oxidized proteins by autophagy during oxidative stress in Arabidopsis. Plant Physiol 2007; 143: 291-299.

22. Kang C, You YJ, Avery L. Dual roles of autophagy in the survival of Caenorhabditis elegans during starvation. Genes Dev 2007; 21: 2161-2171.

23. Melendez A, Talloczy Z, Seaman M, Eskelinen EL, Hall DH, Levine B. Autophagy genes are essential for dauer development and life-span extension in C. elegans. Science 2003; 301: 1387-1391.

24. Kuma A, Hatano M, Matsui M, Yamamoto A, Nakaya H, Yoshimori T et al. The role of autophagy during the early neonatal starvation period. Nature 2004; 432: 1032-1036.

25. Juhasz G, Csikos G, Sinka R, Erdelyi M, Sass M. The Drosophila homolog of Aut1 is essential for autophagy and development. FEBS Lett 2003; 543: 154-158.

26. Hara T, Nakamura K, Matsui M, Yamamoto A, Nakahara Y, Suzuki-Migishima R et al. Suppression of basal autophagy in neural cells causes neurodegenerative disease in mice. Nature 2006; 441: 885-889.
27. Komatsu M, Waguri S, Chiba T, Murata S, Iwata J, Tanida I et al. Loss of autophagy in the central nervous system causes neurodegeneration in mice. Nature 2006; 441: 880-884.

28. Edinger AL, Thompson CB. Death by design: apoptosis, necrosis and autophagy. Curr Opin Cell Biol 2004; 16: 663-669.

29. Lee $\mathrm{CY}$, Baehrecke EH. Steroid regulation of autophagic programmed cell death during development. Development 2001; 128: 1443-1455.

30. Lee CY, Cooksey BA, Baehrecke EH. Steroid regulation of midgut cell death during Drosophila development. Dev Biol 2002; 250: 101-111.

31. Martin DN, Baehrecke EH. Caspases function in autophagic programmed cell death in Drosophila. Development 2004; 131: 275-284

32. Gorski SM, Chittaranjan S, Pleasance ED, Freeman JD, Anderson CL, Varhol RJ et al. A SAGE approach to discovery of genes involved in autophagic cell death. Curr Biol 2003; 13: $358-363$

33. Jiang C, Baehrecke EH, Thummel CS. Steroid regulated programmed cell death during Drosophila metamorphosis. Development 1997; 124: 4673-4683.

34. Lee CY, Clough EA, Yellon P, Teslovich TM, Stephan DA, Baehrecke EH. Genome-wide analyses of steroid- and radiation-triggered programmed cell death in Drosophila. Curr Biol 2003; 13: 350-357.

35. Scott RC, Juhasz G, Neufeld TP. Direct induction of autophagy by Atg1 inhibits cell growth and induces apoptotic cell death. Curr Biol 2007; 17: 1-11.

36. Olie RA, Durrieu F, Cornillon S, Loughran G, Gross J, Earnshaw WC et al. Apparent caspase independence of programmed cell death in Dictyostelium. Curr Biol 1998; 8: 955-958

37. Lam D, Levraud JP, Luciani MF, Golstein P. Autophagic or necrotic cell death in the absence of caspase and bcl-2 family members. Biochem Biophys Res Commun 2007; 363: $536-541$.

38. Roisin-Bouffay C, Luciani MF, Klein G, Levraud JP, Adam M, Golstein P. Developmental cell death in dictyostelium does not require paracaspase. J Biol Chem 2004; 279 : 11489-11494

39. Whittingham WF, Raper KB. Non-viability of stalk cells in dictyostelium. Proc Natl Acad Sci USA 1960; 46: 642-649.

40. Levraud JP, Adam M, Luciani MF, de Chastellier C, Blanton RL, Golstein P. Dictyostelium cell death: early emergence and demise of highly polarized paddle cells. J Cell Biol 2003; 160: 1105-1114.

41. Cornillon S, Foa C, Davoust J, Buonavista N, Gross JD, Golstein P. Programmed cell death in Dictyostelium. J Cell Sci 1994; 107 (Part 10): 2691-2704.

42. Lam D, Kosta A, Luciani MF, Golstein P. The inositol 1,4,5-trisphosphate receptor is required to signal autophagic cell death. Mol Biol Cell 2008; 19: 691-700.

43. Cornillon $\mathrm{S}$, Olie RA, Golstein P. An insertional mutagenesis approach to Dictyostelium cell death. Cell Death Differ 1998; 5: 416-425.

44. Kosta A, Roisin-Bouffay C, Luciani MF, Otto GP, Kessin RH, Golstein P. Autophagy gene disruption reveals a non-vacuolar cell death pathway in Dictyostelium. J Biol Chem 2004; 279: 48404-48409.

45. Laporte C, Kosta A, Klein G, Aubry L, Lam D, Tresse E et al. A necrotic cell death model in a protist. Cell Death Differ 2007; 14: 266-274.

46. Kissova I, Deffieu M, Manon S, Camougrand N. Uth1p is involved in the autophagic degradation of mitochondria. J Biol Chem 2004; 279: 39068-39074.

47. Camougrand N, Grelaud-Coq A, Marza E, Priault M, Bessoule JJ, Manon S. The product of the UTH1 gene, required for Bax-induced cell death in yeast, is involved in the response to rapamycin. Mol Microbiol 2003; 47: 495-506.

48. Zeng $\mathrm{X}$, Overmeyer $\mathrm{JH}$, Maltese WA. Functional specificity of the mammalian Beclin-Vps34 PI 3-kinase complex in macroautophagy versus endocytosis and lysosomal enzyme trafficking. J Cell Sci 2006; 119 (Part 2): 259-270.

49. Maiuri MC, Le Toumelin G, Criollo A, Rain JC, Gautier F, Juin P et al. Functional and physical interaction between $\mathrm{Bcl}-\mathrm{X}(\mathrm{L})$ and a $\mathrm{BH} 3-$ like domain in Beclin-1. Embo J2007; 26: 2527-2539

50. Liang XH, Kleeman LK, Jiang HH, Gordon G, Goldman JE, Berry G et al. Protection against fatal Sindbis virus encephalitis by beclin, a novel Bcl-2-interacting protein. J Virol 1998; 72: 8586-8596.

51. Takacs-Vellai K, Vellai T, Puoti A, Passannante M, Wicky C, Streit A et al. Inactivation of the autophagy gene bec-1 triggers apoptotic cell death in C. elegans. Curr Biol 2005; 15 : 1513-1517.

52. Toth ML, Simon P, Kovacs AL, Vellai T. Influence of autophagy genes on ion-channeldependent neuronal degeneration in Caenorhabditis elegans. J Cell Sci 2007; 120 (Part 6): 1134-1141.

53. Samara C, Tavernarakis N. Autophagy and cell death in Caenorhabditis elegans. Curr Pharm Des 2008; 14: 97-115.

54. van Doorn WG, Woltering EJ. Many ways to exit? Cell death categories in plants. Trends Plant Sci 2005; 10: 117-122.

55. Liu Y, Schiff M, Czymmek K, Talloczy Z, Levine B, Dinesh-Kumar SP. Autophagy regulates programmed cell death during the plant innate immune response. Cell 2005; 121 : 567-577.

56. Yousefi S, Perozzo R, Schmid I, Ziemiecki A, Schaffner T, Scapozza L et al. Calpain-mediated cleavage of Atg5 switches autophagy to apoptosis. Nat Cell Biol 2006; 8 : 1124-1132.

57. Yu L, Alva A, Su H, Dutt P, Freundt E, Welsh $S$ et al. Regulation of an ATG7-beclin 1 program of autophagic cell death by caspase-8. Science 2004; 304: 1500-1502. 
58. Moretti L, Attia A, Kim KW, Lu B. Crosstalk between Bak/Bax and mTOR signaling regulates radiation-induced autophagy. Autophagy 2007; 3: 142-144.

59. Shimizu S, Kanaseki T, Mizushima N, Mizuta T, Arakawa-Kobayashi S, Thompson CB et al. Role of Bcl-2 family proteins in a non-apoptotic programmed cell death dependent on autophagy genes. Nat Cell Biol 2004; 6: 1221-1228.

60. Shao Y, Gao Z, Marks PA, Jiang X. Apoptotic and autophagic cell death induced by histone deacetylase inhibitors. Proc Natl Acad Sci USA 2004; 101: 18030-18035.

61. Kessel D, Reiners Jr JJ. Initiation of apoptosis and autophagy by the $\mathrm{Bcl}-2$ antagonist HA14-1. Cancer Lett 2007; 249: 294-299.

62. Diskin T, Tal-Or P, Erlich S, Mizrachy L, Alexandrovich A, Shohami E et al. Closed head injury induces upregulation of Beclin 1 at the cortical site of injury. J Neurotrauma 2005; 22: 750-762.

63. Erlich S, Shohami E, Pinkas-Kramarski R. Neurodegeneration induces upregulation of Beclin 1. Autophagy 2006; 2: 49-51.

64. Adhami F, Liao G, Morozov YM, Schloemer A, Schmithorst VJ, Lorenz JN et al. Cerebral ischemia-hypoxia induces intravascular coagulation and autophagy. Am J Pathol 2006 169: $566-583$

65. Borsello T, Croquelois K, Hornung JP, Clarke PG. N-methyl-d-aspartate-triggered neuronal death in organotypic hippocampal cultures is endocytic, autophagic and mediated by the c-Jun N-terminal kinase pathway. Eur J Neurosci 2003; 18: 473-485.

66. Tarabal O, Caldero J, Casas C, Oppenheim RW, Esquerda JE. Protein retention in the endoplasmic reticulum, blockade of programmed cell death and autophagy selectively occur in spinal cord motoneurons after glutamate receptor-mediated injury. Mol Cell Neurosci 2005; 29: 283-298.

67. Yue Z. Regulation of neuronal autophagy in axon: implication of autophagy in axonal function and dysfunction/degeneration. Autophagy 2007; 3: 139-141.

68. Sakon S, Xue X, Takekawa M, Sasazuki T, Okazaki T, Kojima Y et al. NF-kappaB inhibits TNF-induced accumulation of ROS that mediate prolonged MAPK activation and necrotic cell death. EMBO J 2003; 22: 3898-3909.

69. Xu Y, Huang S, Liu ZG, Han J. Poly(ADP-ribose) polymerase-1 signaling to mitochondria in necrotic cell death requires RIP1/TRAF2-mediated JNK1 activation. J Biol Chem 2006; 281: 8788-8795

70. Yaglom JA, Ekhterae D, Gabai VL, Sherman MY. Regulation of necrosis of H9c2 myogenic cells upon transient energy deprivation. Rapid deenergization of mitochondria precedes necrosis and is controlled by reactive oxygen species, stress kinase JNK, HSP72 and ARC. J Biol Chem 2003; 278: 50483-50496.

71. Samara C, Syntichaki P, Tavernarakis N. Autophagy is required for necrotic cell death in Caenorhabditis elegans. Cell Death Differ 2008; 15: 105-112.
72. Taylor JP, Hardy J, Fischbeck KH. Toxic proteins in neurodegenerative disease. Science 2002; 296: 1991-1995.

73. Riley BE, Orr HT. Polyglutamine neurodegenerative diseases and regulation of transcription: assembling the puzzle. Genes Dev 2006; 20: 2183-2192.

74. Pandey UB, Nie Z, Batlevi Y, McCray BA, Ritson GP, Nedelsky NB et al. HDAC6 rescues neurodegeneration and provides an essential link between autophagy and the UPS. Nature 2007; 447: 859-863

75. Jia K, Hart AC, Levine B. Autophagy genes protect against disease caused by polyglutamine expansion proteins in Caenorhabditis elegans. Autophagy 2007; 3 $21-25$.

76. Ravikumar B, Vacher C, Berger Z, Davies JE, Luo S, Oroz LG et al. Inhibition of mTOR induces autophagy and reduces toxicity of polyglutamine expansions in fly and mouse models of Huntington disease. Nat Genet 2004; 36: 585-595.

77. Schmelzle T, Hall MN. TOR, a central controller of cell growth. Cell 2000; 103: 253-262.

78. Ravikumar B, Berger Z, Vacher C, O'Kane CJ, Rubinsztein DC. Rapamycin pre-treatment protects against apoptosis. Hum Mol Genet 2006; 15: 1209-1216.

79. Williams A, Sarkar S, Cuddon P, Ttofi EK, Saiki S, Siddiqi FH et al. Novel targets for Huntington's disease in an mTOR-independent autophagy pathway. Nat Chem Biol 2008 4: 295-305.

80. Sarkar S, Floto RA, Berger Z, Imarisio S, Cordenier A, Pasco M et al. Lithium induces autophagy by inhibiting inositol monophosphatase. J Cell Biol 2005; 170: 1101-1111.

81. Ravikumar B, Acevedo-Arozena A, Imarisio S, Berger Z, Vacher C, O'Kane CJ et al. Dynein mutations impair autophagic clearance of aggregate-prone proteins. Nat Genet 2005; 37: 771-776.

82. Arama $\mathrm{E}$, Agapite J, Steller $\mathrm{H}$. Caspase activity and a specific cytochrome $\mathrm{C}$ are required for sperm differentiation in Drosophila. Dev Cell 2003; 4: 687-697.

83. Kuranaga E, Miura M. Nonapoptotic functions of caspases: caspases as regulatory molecules for immunity and cell-fate determination. Trends Cell Biol 2007; 17: 135-144.

84. Zermati Y, Mouhamad S, Stergiou L, Besse B, Galluzzi L, Boehrer S et al. Nonapoptotic role for Apaf-1 in the DNA damage checkpoint. Mol Cell 2007; 28: 624-637.

85. Ogura K, Wicky C, Magnenat L, Tobler H, Mori I, Muller F et al. Caenorhabditis elegans unc-51 gene required for axonal elongation encodes a novel serine/threonine kinase. Genes Dev 1994; 8: 2389-2400.

86. Thumm M, Kadowaki T. The loss of Drosophila APG4/AUT2 function modifies the phenotypes of cut and Notch signaling pathway mutants. Mol Genet Genomics 2001; 266: 657-663.

87. Lum JJ, Bauer DE, Kong M, Harris MH, Li C, Lindsten T et al. Growth factor regulation of autophagy and cell survival in the absence of apoptosis. Cell 2005; 120: 237-248. 